\title{
Position of Impacted Mandibular Third Molar in different Skeletal Facial Tụpes
}

\author{
Dr Manish Raj Sapkota, Dr Shishir Bhatta, ${ }^{2}$ Dr Sujita Shrestha, ${ }^{3}$ Dr Rabindra Man Shrestha \\ 1.2Dental Surgeon, 4Prof, Dept of Orthodontics, \\ 3Lecturer, Dept of Community \& Public Health Dentistry \\ Kantipur Dental College, Kathmandu, Nepal
}

Correspondence: Dr Manish Raj Sapkota; Email: drmanishsapkota@gmail.com

\section{ABSTRACT}

Introduction: Variation in growth pattern in different facial forms affect the space available for tooth eruption, therefore the mandibular third molar impaction has correlation with different skeletal facial types.

Objective: To determine the position of impacted mandibular third molar in different skeletal facial types in Nepalese samples.

Materials \& Method: This cross sectional study was carried out on pre-treatment lateral cephalogram and orthopantomogram records of 207 orthodontic patients visiting Kantipur Dental College and Hospital. Age range of the sample was 16-33 years. Various facial forms were determined with the help of mandibular plane angle (SN-GoGn); for which Nemoceph software was used. Beta angle was used to determine the angle of impaction of mandibular third molar. Impaction pattern was classified as per Pell \& Gregory and Winter's system. SPSS version 20 was used for statistical analysis.

Result: Overall rate of mandibular third molar impaction was $63.77 \%$ (11.11\% unilateral and $52.66 \%$ bilateral impaction). The most common type of impaction bilaterally was mesioangular based on Winter's classification, Class II Position B based on Pell \& Gregory's classification. Higher rate of mandibular third molar impaction was found in dolichofacial type of face (49.2\%).

Conclusion: Decreased mandibular third molar impactions are seen in brachyfacial type compared to mesofacial and dolichofacial types.

Keywords: facial pattern, impaction, mandibular third molar, orthopantomogram

\section{INTRODUCTION}

Impaction is the failure in tooth eruption, which can be a result of obstruction in the eruption path or inappropriate tooth position.' Mandibular third molar is the most commonly impacted tooth. ${ }^{2}$ The etiology of mandibular third molar impaction are inadequate space between distal surface of second molar and anterior border of ramus, ${ }^{3}$ amount and direction of mandibular growth, remodeling and width of ramus, rate of maturation of third molars, inclination of posterior dentition, size of dentition relative to the jaws, and systemic causes. ${ }^{4}$

According to Ricketts, facial morphology can be classified as brachyfacial, mesofacial and dolichofacial. ${ }^{5}$ In dolichofacial face, excessive clockwise rotation of mandible during growth leads to relatively short body. ${ }^{6}$ Lengthening of the body of mandible by anterior resorption and posterior deposition of ramus in brachyfacial face allows adequate space for the third molar to erupt. This remodeling is limited in dolichofacial type leading to inadequate space for third molar eruption. Thus it can be assumed that third molar impaction has correlation with different skeletal facial types.6 The aim of this study was to determine the position of impacted mandibular third molar in different skeletal facial types in Nepalese patient samples.

\section{MATERIALS AND METHOD}

A cross-sectional study was performed on 207 pretreatment lateral cephalogram and orthopantomogram records of patients visiting Department of Orthodontics, Kantipur Dental College and Hospital. The study was conducted during September 2016 to January 2017 after receiving ethical approval from Institutional Review Committee. Inclusion criteria for the study were: complete patient records, pretreatment radiographs showing complete dentition, presence of mandibular third molars with at least two-third of root formation completed, and good quality radiographs. Patients with pathological conditions related to mandibular second and third molars such as extensive caries, cystic lesions were excluded.

All the radiographs were evaluated by a single examiner. Nemoceph software (Dental Studio NX) was used to trace 


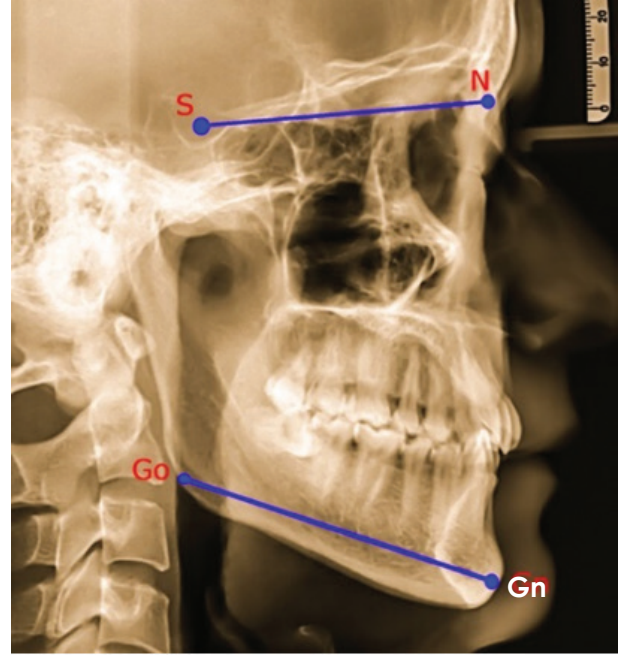

Figure 1: Cephalogram showing mandibular plane angle

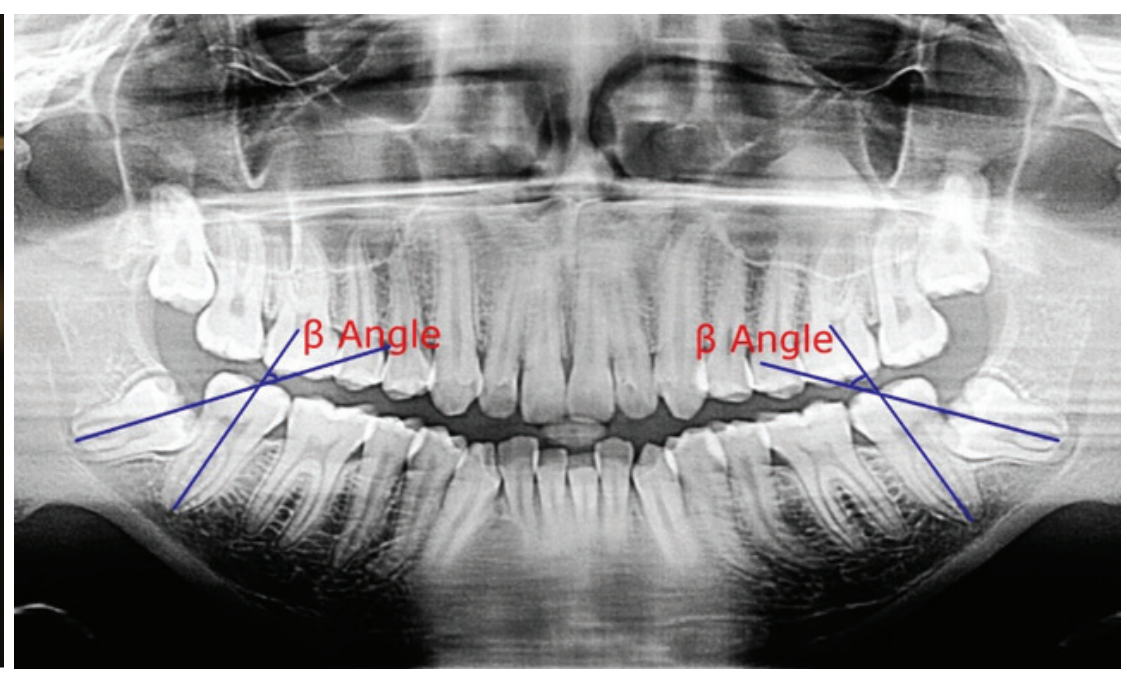

Figure 2: Orthopantomogram showing $\beta$ angle thelateral cephalogramswhereasorthopantomograms were traced manually. The angle between Sella-Nasion line and Gonion-Gnathion line (mandibular plane) was measured using cepholometric protractor; which was termed as SN-GoGn angle or mandibular plane angle (Figure 1). This angle was used to determine different skeletal facial types based on Rickett's classification as shown in the following table. ${ }^{5}$

\begin{tabular}{|l|c|}
\hline \multicolumn{1}{|c|}{$\begin{array}{c}\text { Skeletal facial type } \\
\text { (Rickett's Classification) }\end{array}$} & SN-GoGn Angle \\
\hline Brachyfacial & $<27^{\circ}$ \\
\hline Mesiofacial & $27-37^{\circ}$ \\
\hline Dolichofacial & $>37^{\circ}$ \\
\hline
\end{tabular}

Similarly, the angulation of mandibular third molar impaction was determined by $\beta$ angle; which is the angle between intersecting long axis of mandibular second molar and mandibular third molar drawn through the midpoint of occlusal surface and midpoint of root bifurcation (Figure 2). ${ }^{8}$

\begin{tabular}{|l|c|}
\hline \multicolumn{1}{|c|}{ Mandibular Third Molar Angulations } & $\boldsymbol{\beta}$ angle \\
\hline Distoangular & $\leq-11^{\circ}$ \\
\hline Vertical & $-10-10^{\circ}$ \\
\hline Mesioangular & $11-79^{\circ}$ \\
\hline Horizontal & $\geq 80^{\circ}$ \\
\hline
\end{tabular}

Impaction was also classified according to Pell \& Gregory's classification system based on the amount of space available between distal surface of second molar and anterior border of ramus. ${ }^{9}$

\begin{tabular}{|l|l|}
\hline \multicolumn{2}{|c|}{ Pell \& Gregory's Classification } \\
\hline Class I & $\begin{array}{l}\text { Sufficient amount of space for accommodation } \\
\text { of the mesio-distal diameter of crown of the third } \\
\text { molar }\end{array}$ \\
\hline Class II & $\begin{array}{l}\text { Space between the ramus and distal side of } \\
\text { second molar is less than the mesiodistal diameter } \\
\text { of the third molar }\end{array}$ \\
\hline Class III & $\begin{array}{l}\text { All or most of the third molar is located within the } \\
\text { ramus }\end{array}$ \\
\hline
\end{tabular}

Level of impaction was classified as Position A, B and C; which is related to the occlusal height as compared to the adjacent second molar.?

\begin{tabular}{|l|l|}
\hline \multicolumn{2}{|c|}{ Level of impaction } \\
\hline Position A & At the level of adjacent tooth \\
\hline Position B & $\begin{array}{l}\text { Between occlusal and cervical margins of the } \\
\text { adjacent tooth }\end{array}$ \\
\hline Position C & Below the cervical margin \\
\hline
\end{tabular}

The findings were recorded using a data collection sheet. Kruskal-Wallis test was done to check the relationship of impacted mandibular third molar with different skeletal facial types. Level of significance was set at $p<0.05$. 


\section{RESULT}

The sample comprised of 207 lateral cephalogram and orthopantomogram of the subjects of age range 16-33 (mean 21.04, SD 3.824). Among all, $42.5 \%$ were female and $57.5 \%$ were male. A total of $63.77 \%$ of mandibular third molar was impacted, out of which $11.11 \%$ was unilateral and $52.66 \%$ was bilateral impaction. $59 \%$ of total impaction was seen in female and $41 \%$ in male. The occurrence of mandibular third molar impaction was found to be highest in dolichofacial type of face and least in brachyfacial type (Graph 1). Mesioangular type of impaction was the most common type on both sides of the mandible (Graph 2).

On right side of the mandible, Position A type of impaction was found in $19.3 \%$, Position $B$ in $39.1 \%$ and Position $C$ in $2.9 \%$. Whereas on left side, Position $A$, Position B and position C were found in 17.4\%, $40.1 \%$ and $3.4 \%$ respectively. Various types of impaction according to Pell \& Gregory's classification are shown in Graph 3.

Regarding the angle of impaction, dolichofacial type of face had highest frequency of mesioangular impactions, whereas mesofacial and brachyfacial types had maximum of distoangular impactions (Table 1). Regarding the class of impaction, Class I and Class II impactions were found more in dolichofacial type and Class III in mesofacial type (Table 2). Concerning the position of impaction, the frequency of Position $C$ was found to be more in mesofacial type, while Position A and $\mathrm{B}$ were more in dolichofacial type (Table 3).

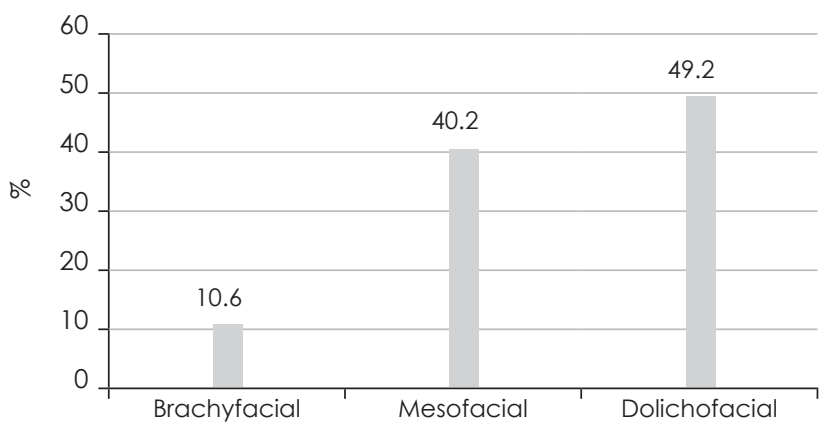

Graph 1: Occurrence of impacted mandibular third molar in different skeletal facial types (\%)

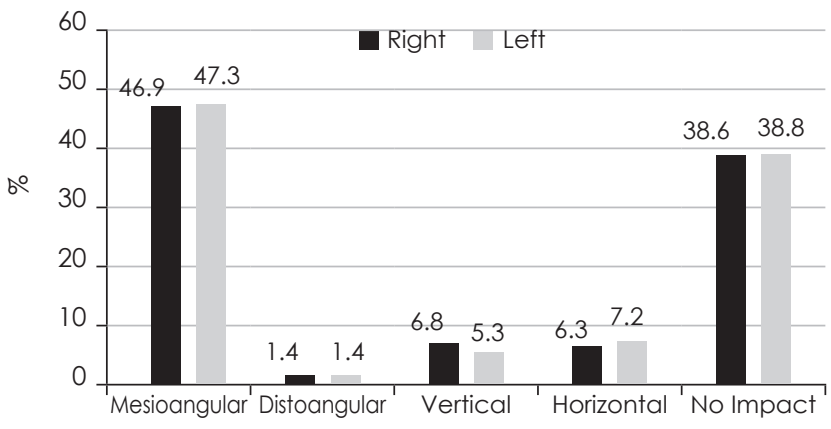

Graph 2: Angulations of third molar impaction on right and left sides (\%)

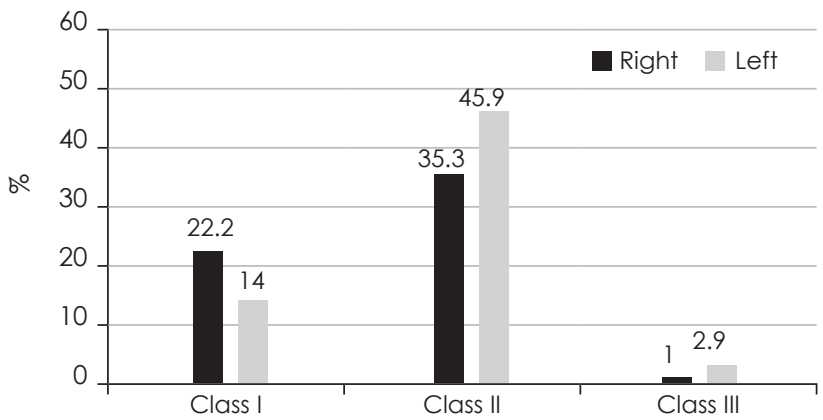

Graph 3: Distribution of impaction according to Pell \& Gregory classification (\%)

Table 1: Angulation of third molar impaction in different skeletal facial types

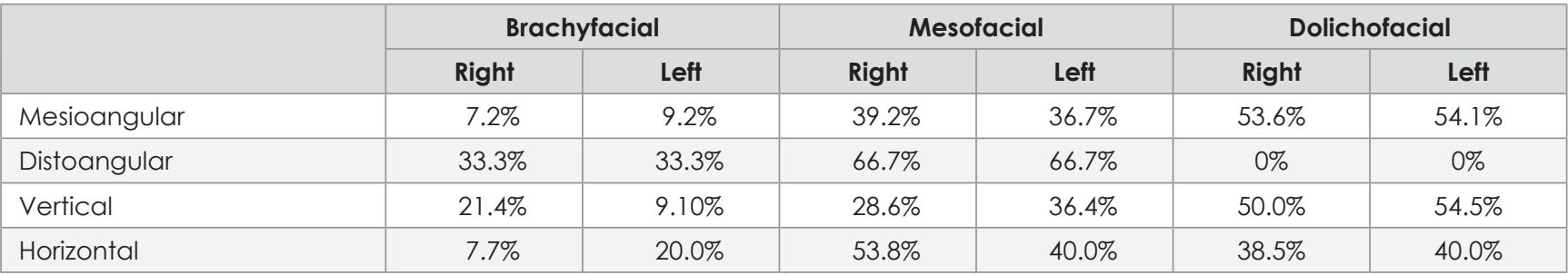

Table 2: Distribution of impaction in various facial types according to Pell \& Gregory Classification

\begin{tabular}{|l|c|c|c|c|c|c|}
\hline \multirow{2}{*}{} & \multicolumn{2}{|c|}{ Brachyfacial } & \multicolumn{2}{c|}{ Mesofacial } & \multicolumn{3}{c|}{ Dolichofacial } \\
\cline { 2 - 7 } & Right & Left & Right & Left & Right & Left \\
\hline Class I & $10.9 \%$ & $10.3 \%$ & $43.5 \%$ & $41.4 \%$ & $45.7 \%$ & $48.3 \%$ \\
\hline Class II & $6.8 \%$ & $11.6 \%$ & $37.0 \%$ & $33.7 \%$ & $56.2 \%$ & $54.7 \%$ \\
\hline Class III & $50.0 \%$ & $16.7 \%$ & $50.0 \%$ & $33.3 \%$ & $0 \%$ & $50.0 \%$ \\
\hline
\end{tabular}


Table 3: Position of mandibular third molar impaction in different skeletal facial types

\begin{tabular}{|l|c|c|c|c|c|c|}
\hline \multirow{2}{*}{} & \multicolumn{2}{|c|}{ Brachyfacial } & \multicolumn{2}{c|}{ Mesofacial } & \multicolumn{2}{c|}{ Dolichofacial } \\
\cline { 2 - 7 } & Right & Left & Right & Left & Right & Left \\
\hline Position A & $12.50 \%$ & $22.20 \%$ & $40.00 \%$ & $41.70 \%$ & $47.50 \%$ & $36.10 \%$ \\
\hline Position B & $7.40 \%$ & $4.80 \%$ & $39.50 \%$ & $33.70 \%$ & $53.10 \%$ & $61.40 \%$ \\
\hline Position C & $33.30 \%$ & $14.30 \%$ & $66.70 \%$ & $42.90 \%$ & $0 \%$ & $42.90 \%$ \\
\hline
\end{tabular}

Table 4: Relationship of mandibular third molar impaction and skeletal facial types

\begin{tabular}{|l|c|c|c|c|}
\hline \multicolumn{1}{|c|}{ Status of mandibular third molar } & Brachyfacial & Mesofacial & Dolichofacial & p-Value \\
\hline No Impaction & $43(75.4 \%)$ & $17(24.3 \%)$ & $15(18.8 \%)$ & \\
\hline Unilateral Impaction & $7(12.3 \%)$ & $13(18.6 \%)$ & $3(3.8 \%)$ & \multirow{2}{*}{$0.000^{*}$} \\
\hline Bilateral Impaction & $7(12.3 \%)$ & $40(57.1 \%)$ & $62(77.5 \%)$ & \\
\hline Total & $57(100 \%)$ & $70(100 \%)$ & $80(100 \%)$ & \\
\hline
\end{tabular}

*Statistically significant at $p<0.05$

Kruskal-Wallis test showed a statistically significant difference between impaction of mandibular third molar and different facial types (Table 4). Subsequently, Post Hoc test depicted significant differences between brachyfacial and mesofacial types ( $p$-Value 0.000), and brachyfacial and dolichofacial types ( $p$-Valve 0.000). However, there was no significant difference between mesofacial and dolichofacial types ( $p$-Valve 0.199).

\section{DISCUSSION}

According to Andreasen et al impaction of mandibular third molar varies from $18-32 \%$ in different populations. ${ }^{10}$ Vilela and Vitol reported the most frequently impacted teeth as third molar (90\%) with the higher prevalence in mandible (60\%) compared to maxilla (30\%). ${ }^{11}$ In this study, the frequency of mandibular third molar impaction was found to be $63.8 \%$.

Short mandibular length provides insufficient space for third molar to erupt causing the impaction. , $12^{2}$ Eroz et al demonstrated shorter length of mandible in dolichofacial patients predisposing to impaction. ${ }^{13}$ Increased occurrence of mandibular third molar impaction was seen in dolichofacial type of face (49.2\%) compared to mesofacial (40.2\%) and brachyfacial (10.6\%). This result is consistent with the previous studies by Bashir et al and Eroz et al .6,13

Mesioangular impaction was the most common type of impaction ( $46.9 \%$ on right and $47.3 \%$ on left) and distoangular was the least common type bilaterally (1.4\%). This finding is in accordance to the study by
Sokri et al. ${ }^{7}$ Breik and Grubber showed that over $80 \%$ of the mandibular third molar impaction in all facial types was in mesioangular position. ${ }^{14}$ Viela and Vitol found that vertical position was most prevalent, followed by mesioangular position contrary to findings by Sandhu et $a^{11,15}$ and Venta et $a^{16}$ where mesioangular position was the most prevalent.

Limitation of our study was the sample size and sample type. As orthodontic patients are more likely to suffer malocclusion and potential crowding, they are also likely to possess higher occurrence of mandibular third molar impaction compared to general population sample. As the study was carried out in a limited sample, the findings cannot be generalized.

\section{CONCLUSION}

Greater horizontal facial growth pattern in brachyfacial subjects provides increased space for the full eruption of mandibular third molars. Decreased mandibular third molar impactions are seen in brachyfacial facial type as compared to mesofacial and dolichofacial. There is significant difference between facial form and presence or absence of mandibular third molar impaction.

\section{Acknowledgement}

Sincere thanks to Dr Jyoti Dhakal and Dr Ujjwal Pyakurel, Faculty, Department of Orthodontics; Dr Sunita Khanal and Dr Rosina Bhattarai, PG Residents, Department of Public Health Dentistry, Kantipur Dental College for their kind support. 


\section{REFERENCES}

1. Raghoebar GM, Boering G, Vissink A, Stegenga B. Eruption disturbances of permanent molars: A review. J Oral Pathol Med. 1991; 20(4):159-66.

2. Kazemian M, Zarch SHH, Banihashemi E, Khajavi M, Morodi E. Frequency of impacted teeth in patients referred to a radiology center and the Radiology Department of Mashhad School of Dentistry. Bangla J Med Sci. 2015; 14(2):165-8.

3. Björk A. Variations in the growth pattern of the human mandible: Longitudinal radiographic study by the implant method. J Dent Res. 1963; 42(1):400-11.

4. Begg P.R. Stone-age man's dentition. Am J Orthod. 1954; 40:298-312, 373-83, 517-31.

5. Franco FCM, Araujo TM, Vogel CJ, Quintão CCA. Brachycephalic, dolichocephalic and mesocephalic: Is it appropriate to describe the face using skull patterns? Dent Press J Orthod. 2013; 18(3):159-63.

6. Bashir S, Rasool G, Afzal F, Hassan N. Incidence of Mandibular third molar impaction in different facial types of orthodontic patients seen at Khyber College of Dentistry. Pak Oral Dent J.2016; 36(2):232-4.

7. Shokri A, Mohmoudzadeh M, Baharvand M, Mortazavi H, Faradmal J, Khajeh S, Yousefi F, Gangachin MN. Position of impacted mandibular third molar in different skeletal facial types: First radiographic evaluation in a group of Iranian patients. Imaging Sci Dent. 2014; 44(1):61-5.

8. AL-Khateeb TH, Bataineh AB. Pathology associated with impacted mandibular third molars in a group of Jordanians. J Oral MaxillofaC Surg. 2006; 64(11):1598-602.

9. Grover PS, Lorton L. The incidence of unerupted permanent teeth and related clinical cases. Oral Surg Oral Med Oral Pathol.1985; 59:425.

10. Andreasen JO, Petersen JK, Laskin DM, Textbook and color atlas of tooth impactions: Diagnosis, treatment, prevention. Copenhagen: Munksgaard; 1997.p. 222-3.

11. Vilela EM, Vitoi PA. Study of position and eruption of lower third molars in adolescents. South Braz Dent J. 2011 ; 8:390-7.

12. Ricketts RM. Studies leading to the practice of abortion of lower third molars. Dent Clin N Am. 1979; 23:393-41 1.

13. Eroz B, Ceylan I, Aydemir S. An investigation of mandibular morphology in subjects with different vertical facial growth patterns. Aus Orthod J. 2000; 16:16-21.

14. Breik O, Grubor D. Incidence of mandibular third molar impactions in different skeletal face types. Aus Dent J. $2008 ; 53(4): 320-4$.

15. Sandhu S, Kaur T. Radiographic evaluation of the status of third molars in the Asian-Indian students. J Oral Maxillofac Surg. 2005; 63:640-5.

16. Venta I, Turtola L, Ylipaavalniemi P. Radiographic follow-up of impacted third molars from age 20-32 years. Int J Oral Maxillofac Surg. 2001; 30:54-7. 